\title{
Epidemiology of intestinal helminthiasis among school children with emphasis on Schistosoma mansoni infection in Wolaita zone, Southern Ethiopia
}

\author{
Bereket Alemayehu ${ }^{1 *}$, Zewdneh Tomass ${ }^{1}$, Fiseha Wadilo², Dawit Leja', Song Liang ${ }^{3}$ and Berhanu Erko ${ }^{4}$
}

\begin{abstract}
Background: Intestinal helminth infections are major parasitic diseases causing public health problems in Ethiopia. Although the epidemiology of these infections are well documented in Ethiopia, new transmission foci for schistosomiasis are being reported in different parts of the country. The objective of this study was to assess the prevalence of Schistosoma mansoni and other intestinal helminth infections among school children and determine the endemicity of schistosomiasis in Wolaita Zone, southern Ethiopia.
\end{abstract}

Methods: Cross-sectional parasitological and malacological surveys were conducted by collecting stool samples for microscopic examination and snails for intermediate host identification. Stool samples were collected from 503 children and processed for microscopic examination using Kato-Katz and formalin-ether concentration methods. Snails collected from aquatic environments in the study area were identified to species level and Biomphalaria pfeifferi snails, the intermediate host of S. mansoni, were individually exposed to artificial light in order to induce cercariae shedding. Cercariae shed from snails were used to infect laboratory-bred Swiss albino mice in order to identify the schistosome to species level.

Results: The overall prevalence of intestinal helminth infections was $72.2 \%$ among school children. S. mansoni infection prevalence was $58.6 \%$. The prevalence and intensity of S. mansoni infections varied among schools and sex of children. Swimming was the only factor reported to be significantly associated with S. mansoni infection $(\mathrm{AOR}=2.954,95 \% \mathrm{Cl}: 1.962-4.449)$. Other intestinal helminth species identified were hookworms (27.6\%), Ascaris lumbricoides (8.7\%), E. vermicularis (2.8\%), Taenia species (2.6\%), T. trichiura (1.2\%) and H. nana (0.6\%). Only B. pfeifferi snails collected from streams shed schistosome cercariae and 792 adult $S$. mansoni worms were harvested from mice exposed to cercariae shed from B. pfeifferi on the 6th week post-exposure.

Conclusion: The present study found high level of intestinal helminth infections in the study area. The study also confirmed autochthonous transmission and endemicity of S. mansoni as evidenced by both parasitological and malacological findings as well as by further establishing infections in lab-bred mice. Therefore, there is a need to include the area in the control programs with anti-helminth drugs and also consider other complementary measures including sanitation, provision of clean water supply, and snail control.

Keywords: Schistosoma mansoni, Biomphalaria Pfeifferi, Intestinal helminths, Epidemiology, Endemicity, School children, Wolaita zone, Ethiopia

\footnotetext{
* Correspondence: bereketalemayehu@gmail.com

${ }^{1}$ Biomedical Sciences Division, Department of Biology, College of Natural and

Computational Sciences, Wolaita Sodo University, Wolaita Sodo, Ethiopia

Full list of author information is available at the end of the article
}

(c) The Author(s). 2017 Open Access This article is distributed under the terms of the Creative Commons Attribution 4.0 International License (http://creativecommons.org/licenses/by/4.0/), which permits unrestricted use, distribution, and reproduction in any medium, provided you give appropriate credit to the original author(s) and the source, provide a link to the Creative Commons license, and indicate if changes were made. The Creative Commons Public Domain Dedication waiver (http://creativecommons.org/publicdomain/zero/1.0/) applies to the data made available in this article, unless otherwise stated. 


\section{Background}

Intestinal helminth infections are among the most common infections worldwide. Globally 4.5 billion people are estimated at risk and more than 2 million are ill as a result of soil-transmitted helminths (STHs) infections in areas where sanitation is inadequate and water supplies are unsafe [1].

Schistosomiasis is also a common helminthiasis affecting more than 200 million people globally [1]. The global disease burden caused by schistosomiasis alone is estimated at 4.5 million disability-adjusted life years (DALYs) [2]. The disease is endemic in many countries of the world with over $90 \%$ of cases occurring in subSaharan Africa $[3,4]$. Among the world population, it has been estimated that approximately 779 million people are at risk of schistosome infection [5-7].

Schistosomiasis is one of the major public health problems in Ethiopia. The two species of schistosome causing the disease in the country are $S$. mansoni and S. haematobium. Infections by the parasites usually occur in agricultural communities along small streams, irrigation schemes and lakes at altitudes ranging from 1300 to $2000 \mathrm{~m}$ above sea level (a.s.l) for S. mansoni and below $800 \mathrm{~m}$ a.s.l for S. haematobium [8-10]. Regarding distribution of the two schistosome species in Ethiopia, $S$. mansoni is widely distributed and S. haematobium is confined to the lowland areas of the country [9].

Presence of humans carrying the parasites and fresh water bodies harboring the snail intermediate hosts coupled with the suitable climatic conditions contribute to endemicity of both S. mansoni and S. haematobium infections in several localities in Ethiopia [9-16]. Furthermore, population movement and expansion of water resource development projects are playing key roles in establishing the parasite transmission in new areas in the country [9-11]. In Ethiopia, S. mansoni is transmitted by B. pfeifferi and B. sudanica while $S$. haematobium is transmitted by Bulinus abyssinicus and $B u$. africanus snail intermediate hosts. B. pfeifferi has a wider geographical distribution, whereas $B$. sudanica is distributed in few low land areas of Ethiopia [17, 18]. Even though about 10 bulinid species are reported to exist in Ethiopia, only $\mathrm{Bu}$. abyssinicus and $\mathrm{Bu}$. africanus are found naturally transmitting $S$. haematobium in the country [15]. It has been reported in previous studies that $B u$. Abyssinicus serves as the primary intermediate host for S. heamatobium in Awash valley, whereas $B u$. africanus is dominant in Kurmuk (an area located near to Sudan) [9].

Although several studies have been conducted on the distribution and prevalence of intestinal helminthiasis and schistosomiasis in other parts of Ethiopia [9-19], only limited work was done to determine the prevalence and associated risk factors for these infections in rural villages in the present study area [19]. No epidemiological studies focusing on the parasite and intermediate hosts have been conducted in the area to determine the establishment of S. mansoni transmission. Therefore, the present epidemiological study aimed to assess the prevalence of S. mansoni and other intestinal helminth infections among school children and determine the establishment of $S$. mansoni transmission in the study area by conducting parasitological and malacological techniques as well as by establishing infections in lab-bred mice.

\section{Methods \\ Study areas}

The study was conducted in Wolaita Zone, located in the Southern Nations Nationalities and Peoples Region (SNNPR), Ethiopia. Wolaita Zone is about $329 \mathrm{kms}$ south of Addis Ababa, Ethiopia. The Zone covers a total area of $4541 \mathrm{~km}^{2}$ and has an estimated population of 1.7 million [20]. Administratively, the Zone is divided into 12 districts and 3 town administrations. This Zone is one of the most densely populated Zones in the country with an average of 290 people per square kilometer. The majority of people living in the Zone earn their livelihood from subsistence farming [21]. Agro-ecologically, Wolaita is composed of 3 agro-ecological zones: 9\% highland ("dega"), 56\% midland temperate ("woinadega"), and 35\% lowland ("kolla"), with altitude ranging from below $1000 \mathrm{~m}$ at the foot of Omo River Valley to $3000 \mathrm{~m}$ above sea level at Mount Damota. The average annual temperature varies from $15{ }^{\circ} \mathrm{C}$ to $30{ }^{\circ} \mathrm{C}$, and the rainy season is bimodal with a shorter one starting from February to May and a longer rainy season lasting from June to August. The average annual rainfall of the Zone is $1350 \mathrm{~mm}$. There are currently one governmental and two nongovernmental hospitals and eleven health centers in the zone.

\section{Study design and population}

A cross-sectional study was carried out between January and February 2015 to determine the endemicity of $S$. mansoni infection in the study area, and assess the prevalence and associated risk factors of intestinal helminth infections among school children of five purposively selected primary schools of the rural kebeles (the smallest administrative units in Ethiopia) in close proximity to rivers and streams suspected as sources of schistosomiasis in the Zone. Purposive sampling of the schools was done based on schistosomiasis case information obtained from the health centers in the districts where the target primary schools are located.

School administrators were requested to provide students' enrollment list. Students of grade 1-8 were selected because of their age limit that coincides with the 
standard age range (5-19 years) for schistosomiasis survey as set by World Health Organization (WHO). In each selected primary school, one classroom was randomly selected in each grade from grades 1 to 8 . Then the study subjects were selected by systematic random sampling using their enrollment list as a sampling frame. Each selected subject was registered in a separate registration format and invited to participate in the study.

\section{Sample size determination}

The sample size needed for this study was calculated using single proportion formula at $95 \%$ confidence interval $(\mathrm{CI})$ level $(\mathrm{Z} \alpha / 2=1.96)$, assuming a previous prevalence of $S$. mansoni infection at $81.3 \%$, as a baseline prevalence in the study area [19] and 5\% marginal error. Then the sample size was calculated as $\mathrm{n}=(\mathrm{Z \alpha} / 2)^{2} * \mathrm{P}$ $(1-P) / d^{2}[22]$, where $\mathrm{n}$ is minimum number of sample size, $\mathrm{P}$ is expected prevalence, $\mathrm{Z} \alpha / 2$ is $\mathrm{CI}$ of $95 \%$, and $\mathrm{d}$ is marginal error to be tolerated. To adjust for possible loss of effectiveness using the two-stage cluster sampling and obtain a comparable sample size, the design effect of 2 (assuming the sample variance is 2 time bigger than it would be under simple random sampling) was considered in the sample size estimation. By adding $10 \%$ for non-respondent rate, the final sample size was determined to be 515 .

\section{Stool sample collection and examination}

Stool samples were collected from school children who had no history of taking anti-helminthic drug in the past three months. Children who had no apparent chronic infections and were able to give stool samples were included in the study. Each study subject was given a plastic sheet with an applicator stick to bring approximately $4 \mathrm{~g}$ stool sample. A portion of the stool sample was used to prepare a single Kato-Katz slide in the field [23]. The remaining portion of the stool was transferred to stool cup and preserved in sodium acetate acetic acid formalin (SAF) solution for concentration technique [24]. KatoKatz slides and the preserved stool samples were transported to the Biomedical Science Laboratory, Department of Biology, Wolaita Sodo University, for microscopic examination. A Kato-Katz slide prepared for each child was used for identification and egg count of S. mansoni and determination of the presence and absence of other intestinal helminths except for hookworms. Since a template delivering $41.7 \mathrm{mg}$ of stool was used to prepare Kato-Katz slides, the egg of $S$. mansoni in the slide was counted and the number of eggs was multiplied by 24 to convert into eggs per gram of stool (EPG). The intensity of $S$. mansoni infection was calculated as the geometric mean for infected children and classified based on the intensity classes recommended by WHO as light (1-99 epg), moderate (100- $399 \mathrm{epg}$ ) and heavy (epg $\geq 400)$ [25].
Snail survey and laboratory-mice infection

Snail intermediate hosts were surveyed in natural and man-made water bodies in the study areas. Decaying woods, plant remains, submerged vegetation and stones were searched for snails by trained field collectors using standard snail scoops or by hand picking using gloves and forceps. The same collectors scooped for snails in the surveys to standardize the sampling. Collected snails were placed in plastic buckets containing aquatic weeds and labeled for each collection site before transporting to Aklilu Lemma Institute of Pathobiology for identification, determination of infection by schistosome and maintaining the lifecycle of the parasite in mice. Snails were identified using shell morphology [26, 27].

B. pfeifferi snails were placed individually in shedding vials containing de-chlorinated water, and exposed to artificial light for about half an hour to induce shedding of cercariae. Laboratory-bred albino mice were exposed to cercariae for about $30 \mathrm{~min}$ by immersing in beakers containing cercariae infested water. Feces of mice were checked for the presence of schistosome eggs on day 43 post exposure. Mice were perfused [28] for harvesting of schistosome worms from blood vessels around the mesentery on day 45 post exposure.

\section{Data analysis}

Statistical analysis was performed by using SPSS software version 17. Prevalence and intensity of $S$. mansoni infection were reported in percent and mean eggs per gram stool (EPG), respectively. Bivariate and multivariable logistic regressions were used to select candidate variables and determine the magnitude of association between $S$. mansoni infection and risk factors (age, sex, knowledge about schistosomiasis, herding cattle near river/stream, and reason for contact to water sources) by computing Odds Ratios (ORs) at 95\% confidence level. All probability values were considered statistically significant when the calculated $P$-values were equal to or less than 0.05 .

\section{Ethical considerations}

The protocol of this study was reviewed and approved by the Ethical Review Committee of College of Natural and Computational Science in Wolaita Sodo University. Permissions were obtained from Wolaita Zone Health Department, District Health and Educational Bureaus to conduct the study. The objective of the study was explained to the school administration, primary health care providers and parents/guardian of the children. Verbal consent for the children was obtained from their parents/guardians. As most of the study population were illiterate, the ethical review committee endorsed oral consenting of the parents/guardians of the children. All children found positive for intestinal helminths were 
treated with appropriate drugs by nurses. The infection intensity and prevalence were reported to the Zonal and District Health Offices. The protocol for animal use was also reviewed and approved by the Ethical Review Committee of College of Natural and Computational Science in Wolaita Sodo University (Permit Number: EA-CNCS-07-R02). Handling of Swiss albino mice for sacrifice was performed under anesthesia, and all efforts were made to minimize suffering. The field study protocol of this research was also viewed and approved by the same ethical review committee.

\section{Results}

Socio-demographic characteristics and parasite infections A total of 503 school children $(287$ males and 216 females) aged 5 to 19 participated in the present study with $98 \%$ response rate from five primary schools (Table 1). Seven different species of intestinal helminth parasites including S. mansoni, hookworms, Ascaris lumbricoides, Trichuris trichiura, Taenia species, Hymenolepis nana and Enterobius vermicularis were identified by both Kato-Katz and sodium acetate-acetic acid-formalin (SAF) concentration methods (Table 2). Among the school children examined for intestinal helminths, $72.2 \%$ were found positive for at least one of the helminth parasites identified. The highest prevalence of infection was due to $S$. mansoni (58.6\%) followed by hookworm (27.6\%) and $A$. lumbricoides (8.7\%). Infections by $E$. vermicularis $(2.8 \%)$, Taenia species (2.6\%), T. trichiura
(1.2\%) and H. nana (0.6\%) were less prevalent (Table 2). Among the five primary schools, the highest $S$. mansoni infection prevalence (75\%) was observed in Gilo-Bisare, followed by $71 \%$ in Motala, $58.4 \%$ in Ajora, $40.6 \%$ in Bisare and $5.1 \%$ in Ello. Varying prevalence of major soil transmitted helminths was also observed among the schools (Table 3). Among the age categories, school children in the 5-9 and 10-14 years age group were highly infected. The prevalences of intestinal helminth infection by school were observed as $83.3 \%$ in Gilo-Bisare, $77.1 \%$ in Motala, $74.5 \%$ in Ajora, $46.9 \%$ in Bisare and $44.1 \%$ in Ello. Although there was no absolute dependence on a single water source for drinking and household consumption, pipe water pumped from the underground was the most $(51.7 \%)$ utilized followed by the spring water (30\%) and surface water (21.7\%). $41.4 \%$ of children had either sometimes or never been informed about hygiene practices at home by their parents (Table 1).

\section{Intensity of Schistosoma mansoni infection}

The overall geometric mean of faecal egg counts for $S$. mansoni was 189 EPG (ranged from 24 to 8736 EPG). Overall, 90 (34.2\%) light, 94 (35.5\%) moderate and 79 (30\%) heavy intensity of S. mansoni infections among school children were observed. Among the age groups, the highest (24\%) heavy intensity of infection was found in the 10-14 years age group. Males had more (16.7\%) heavy infection intensity than females (13.3\%). Among the schools, the highest heavy intensity of infection

Table 1 Prevalence of intestinal helminth infections with respect to socio-demographic characteristics of the study participants in Wolaita Zone, southern Ethiopia in 2015

\begin{tabular}{|c|c|c|c|c|}
\hline Variables & & Positive $n(\%)$ & Negative $n(\%)$ & Total n(\% \\
\hline \multirow[t]{2}{*}{ Sex } & Male & $215(74.9)$ & $72(25.1)$ & 287 \\
\hline & Female & $148(68.5)$ & $68(31.5)$ & 216 \\
\hline \multirow[t]{3}{*}{ Age (Year) } & $5-9$ & $66(74.2)$ & $23(25.8)$ & 89 \\
\hline & $10-14$ & $269(72.7)$ & $101(27.3)$ & 370 \\
\hline & $15-19$ & $28(63.6)$ & $16(36.4)$ & 44 \\
\hline \multirow[t]{5}{*}{ Schools } & Ajora & $111(74.5)$ & $38(25.5)$ & 149 \\
\hline & Gilo-Bisare & $110(83.3)$ & $22(16.7)$ & 132 \\
\hline & Bisare & $15(46.9)$ & $17(53.1)$ & 32 \\
\hline & Motala & $101(77.1)$ & $30(22.9)$ & 131 \\
\hline & Ello & $26(44.1)$ & $33(55.9)$ & 59 \\
\hline \multirow[t]{4}{*}{ Source of drinking water } & Pipe & $194(74.6)$ & $66(25.4)$ & 260 \\
\hline & Wells & $7(87.5)$ & $1(12.5)$ & 8 \\
\hline & Spring & $117(77.5)$ & $34(22.5)$ & 151 \\
\hline & Surface water & $69(63.3)$ & $40(36.7)$ & 109 \\
\hline \multirow[t]{3}{*}{ Hygiene education by parents } & No & $15(74)$ & $5(26)$ & 20 \\
\hline & Sometimes & 133(70.7) & 55 (29.3) & 188 \\
\hline & Regularly & $215(72.9)$ & $80(27.1)$ & 295 \\
\hline
\end{tabular}


Table 2 Prevalence of intestinal helminth parasites in school children in Wolaita Zone, southern Ethiopia in 2015

\begin{tabular}{lllr}
\hline Parasites & Positive & Negative & Prevalence \\
\hline Schistosoma mansoni & 295 & 208 & 58.6 \\
Ascaris lumbricoides & 44 & 459 & 8.7 \\
Hookworms & 139 & 364 & 27.6 \\
Trichuris trichiura & 6 & 497 & 1.2 \\
Taenia species & 13 & 490 & 2.6 \\
Hymenolepis nana & 3 & 500 & 0.6 \\
Enterobius vermicularis & 14 & 489 & 2.8 \\
Overall infection & 363 & 140 & 72.2 \\
\hline
\end{tabular}

(15.6\%) was observed in Motala followed by Gilo-Bisare (6.8\%) and Ajora (6.5\%). On the other hand, the light infections were reported for 34 children (12.9\%) in Ajora, $27(10.3 \%)$ in Gilo-Bisare, 25 (9.5\%) in Motala, and 4 (1.5\%) for Bisare primary schools (Table 4).

\section{Risk factors associated with S. mansoni infection}

Visual observations on droppings of human feces around water sources showed that people defecated in open field near rivers, streams and irrigation canals in the study area. It was also observed during visual field survey that human water contact activities in these study areas were also high. All of the school children visited the water bodies at least once in a week, either for swimming, washing clothes, bathing, or fetching water (Table 4). The multivariate logistic analysis showed that school children who swam in rivers and streams were 3 times more likely to be infected with $S$. mansoni than those who did not $(\mathrm{AOR}=2.954$, 95\% CI:1.962-4.449) (Table 5). Although the AORs of some important variables such as sex and herding cattle near water bodies were not statistically significant, their COR showed significant difference (Table 5). There was no significant difference observed between $S$. mansoni infection and factors such as age and knowledge about the disease $(P>0.05)$ (Table 5).

\section{Snail survey}

Streams (Bisare and Kote), rivers (Woibo and Adacha) and Himbecho irrigation canal were surveyed for intermediate hosts during February and March 2015 and snails were collected using a scoop. Among the water bodies surveyed, Woibo and Adacha rivers harbored few and young B. pfeifferi attached to decaying wood, fallen leaves and stems of aquatic weeds.

A total of 256 snails (125 Bulinus species, 111 B. pfeifferi and 20 Lymnaea natalensis) were collected from Himbecho-Irrigation canal (15.6\%), Kote (45.7\%) and Bisare Streams (38.7\%). B. pfeifferi collected from Kote and Bisare Streams shed schistosome cercariae. Ova were not observed in fecal materials from mice exposed to cercariae when checked at day 42 post exposure. Mice were sacrificed at day 45 post-exposure. A total of 792 schistosome worms were recuperated through perfusion of which 87 coupled S. mansoni adults were harvested from blood vessels around the mesentery of the mice (Table 6).

Observation on physical characteristics of the water bodies during the snail survey showed that Bisare and Kote streams were slightly turbid (having less suspended matter), and covered with abundant weeds, algae and other garbage droppings making the water environment conducive for snail existence. Both streams were relatively smaller and slow flowing as compared to the Woibo and Adacha Rivers. The muddy substratum of the streams favored the growth of both emergent and submerged plants.

\section{Discussion}

Intestinal helminth infections are common public health problems in areas where sanitation is inadequate and water supplies are unsafe. Among these infections, soil transmitted helminthiasis due to A. lumbricoides, hookworms and T. trichiura, and schistosomiasis due to $S$. haematobium and S. mansoni are the most common in sub-Saharan Africa [29] These infections also remain considerable public health problems in Ethiopia and

Table 3 Prevalence of Schistosoma mansoni and soil transmitted helminths (STH) infections (pooled result of Kato-Katz and SAF concentration methods) among school children in Wolaita Zone, southern Ethiopia in 2015

\begin{tabular}{|c|c|c|c|c|c|c|c|c|c|c|c|}
\hline \multirow{2}{*}{$\begin{array}{l}\text { Helminth } \\
\text { species }\end{array}$} & \multicolumn{3}{|c|}{ Age (Year) } & \multicolumn{2}{|l|}{ Sex } & \multicolumn{5}{|l|}{ School } & \multirow{2}{*}{$\begin{array}{l}\text { Overall } \\
\text { prevalence (\% }\end{array}$} \\
\hline & $\begin{array}{l}5-9 \\
(n=89)\end{array}$ & $\begin{array}{l}10-14 \\
(n=370)\end{array}$ & $\begin{array}{l}15-19 \\
(n=44)\end{array}$ & $\begin{array}{l}\text { Male } \\
(n=287)\end{array}$ & $\begin{array}{l}\text { Female } \\
(n=216)\end{array}$ & $\begin{array}{l}\text { Ajora } \\
(n=149)\end{array}$ & $\begin{array}{l}\text { Gilo-Bisare } \\
(n=132)\end{array}$ & $\begin{array}{l}\text { Bisare } \\
(n=32)\end{array}$ & $\begin{array}{l}\text { Motala } \\
(n=131)\end{array}$ & $\begin{array}{l}\text { Ello } \\
(n=59)\end{array}$ & \\
\hline $\begin{array}{l}\text { Schistosoma } \\
\text { mansoni }\end{array}$ & $52(58.4)$ & $221(59.7)$ & $22(50)$ & $180(62.7)$ & $115(53.2)$ & 87 (58.4) & $99(75)$ & $13(40.6)$ & $93(71)$ & $3(5.1)$ & 58.6 \\
\hline $\begin{array}{l}\text { Ascaris } \\
\text { lumbricoides }\end{array}$ & $7(7.9)$ & $37(10)$ & 0 & $23(8)$ & $21(9.7)$ & $33(22.1)$ & $9(6.8)$ & 0 & $1(0.8)$ & $1(1.7)$ & 8.7 \\
\hline Hookworms & $25(28.1)$ & $104(28.1)$ & $10(22.7)$ & $88(30.7)$ & 51 (23.6) & $42(28.2)$ & 38 (28.8) & 0 & $36(27.5)$ & $23(39)$ & 27.6 \\
\hline $\begin{array}{l}\text { Trichuris } \\
\text { trichiura }\end{array}$ & 0 & $4(1.1)$ & $2(4.5)$ & $4(1.4)$ & $2(0.9)$ & $1(0.7)$ & $2(1.5)$ & 0 & $2(1.5)$ & $1(1.7)$ & 1.2 \\
\hline
\end{tabular}


Table 4 Intensity of Schistosoma mansoni infection in school children in Wolaita Zones, southern Ethiopia, in 2015

\begin{tabular}{|c|c|c|c|c|}
\hline \multirow[t]{2}{*}{ Variables } & & \multicolumn{3}{|c|}{ Classes of intensity of infection $^{a}$} \\
\hline & & Light n (\%) & Moderate n (\%) & Heavy $n(\%)$ \\
\hline \multirow[t]{3}{*}{ Age (Years) } & $5-9$ & $17(6.5)$ & $14(5.3)$ & $12(4.6)$ \\
\hline & $10-14$ & $65(24.7)$ & $75(28.5)$ & $63(24)$ \\
\hline & $15-19$ & $8(3)$ & $5(1.9)$ & $4(1.5)$ \\
\hline \multirow[t]{2}{*}{ Sex } & Male & $55(20.9)$ & $66(25.1)$ & $44(16.7)$ \\
\hline & Female & $35(13.3)$ & $28(10.6)$ & $35(13.3)$ \\
\hline \multirow[t]{4}{*}{ Schools } & Ajora & $34(12.9)$ & $32(12.2)$ & $17(6.5)$ \\
\hline & Gilo-Bisare & $27(10.3)$ & $36(13.7)$ & $18(6.8)$ \\
\hline & Bisare & $4(1.5)$ & $3(1.1)$ & $3(1.1)$ \\
\hline & Motala & $25(9.5)$ & $23(8.7)$ & $41(15.6)$ \\
\hline \multirow[t]{2}{*}{ Water contact frequency per week } & $\leq 2$ days & $27(10.3)$ & $22(8.4)$ & $29(11)$ \\
\hline & $\geq 3$ days & $63(24)$ & $72(27.4)$ & $50(19)$ \\
\hline \multirow[t]{2}{*}{ Reason for water contact } & Swimming & $77(29.3)$ & $78(29.7)$ & $56(21.3)$ \\
\hline & Other & $13(4.9)$ & $16(6.1)$ & $23(8.7)$ \\
\hline Overall intensity & For total positive $(n=263)$ & $90(34.2)$ & $94(35.8)$ & $79(30)$ \\
\hline
\end{tabular}

a Classes of intensity for S. mansoni infection were set by WHO based on epg count as light (1-99 epg), moderate (100- 399 epg) and heavy (epg $\geq 400)$ [24]

knowledge of high-risk localities is required to inform control interventions in such areas. Even though the mapping of schistosomiasis and soil-transmitted-helminthiasis have already been done in Ethiopia, continuous survey of the disease is needed to accommodate recent discoveries of new transmission foci possibly associated with expansion of water development projects and human movement in the country [14]. In line with this, there are recent reports on intestinal helminthiasis including schistosomiasis from the present study area $[19,30]$. In the present study, the prevalence of intestinal helminth infections was determined and the endemicity of $S$. mansoni infection was established for the first time as evidenced by both parasitological and malacological surveys. The overall 72.3\% prevalence of intestinal helminths including S. mansoni infections found in this study showed that intestinal helminth infections represent a considerable health problem in the study area.

In this study, varying magnitude of prevalence of infections by $S$. mansoni, hookworms, A. lumbricoides, $T$. trichiura, Taenia species, $H$. nana and $E$. vermicularis were found. These infections occurred in almost all of the areas under study. The distribution of these parasites over the study sites might reflect the existence of comparatively similar level of intestinal helminth infection condition in the area. Regarding STH infection, hookworms and $A$.

Table 5 Association of S. mansoni infection with risk factors among school children in Wolaita Zones, southern Ethiopia in 2015

\begin{tabular}{|c|c|c|c|c|c|c|c|c|c|c|}
\hline \multirow[t]{2}{*}{ Variable } & & \multirow[t]{2}{*}{ Positive } & \multirow[t]{2}{*}{ Negative } & \multirow[t]{2}{*}{ COR } & \multicolumn{2}{|c|}{ 95\% C.I. } & \multirow[t]{2}{*}{$\mathrm{AOR}$} & \multicolumn{2}{|c|}{$95 \%$ C.I. } & \multirow{2}{*}{$\begin{array}{l}P \text { - } \\
\text { value }\end{array}$} \\
\hline & & & & & Lower & Upper & & Lower & Upper & \\
\hline \multirow[t]{3}{*}{ Age } & $5-9$ & 66 & 23 & 1.00 & & & 1.00 & & & \\
\hline & $10-14$ & 269 & 101 & 1.055 & 0.660 & 1.689 & 0.885 & 0.538 & 1.458 & 0.632 \\
\hline & $15-19$ & 28 & 16 & 0.712 & 0.344 & 1.470 & 0.656 & 0.306 & 1.404 & 0.277 \\
\hline \multirow[t]{2}{*}{ Sex } & Male & 215 & 72 & 1.00 & & & 1.00 & & & 0.513 \\
\hline & Female & 148 & 68 & 0.677 & 0.473 & 0.969 & 0.871 & 0.575 & 1.319 & \\
\hline \multirow[t]{2}{*}{ Knowledge on disease } & No & 266 & 172 & 1.00 & & & 1.00 & & & 0.260 \\
\hline & Yes & 29 & 36 & 0.521 & 0.308 & 0.881 & 0.722 & 0.410 & 1.272 & \\
\hline \multirow[t]{2}{*}{ Herding cattle } & No & 113 & 97 & 1.00 & & & 1.00 & & & 0.398 \\
\hline & Yes & 182 & 111 & 1.407 & 0.982 & 2.017 & 1.194 & 0.792 & 1.799 & \\
\hline \multirow[t]{2}{*}{ Purpose of water contact } & Other purpose & 61 & 95 & 1.00 & & & 1.00 & & & 0.000 \\
\hline & Swimming & 234 & 113 & 3.225 & 2.179 & 4.774 & $2.954 *$ & 1.962 & 4.449 & \\
\hline
\end{tabular}

Variables adjusted: Age group, Sex, Know on disease, Herding cattle, purpose of water contact

*Significant association $(P \leq 0.05)$ 
Table 6 Snails surveyed from water sources near human settlements in Wolaita Zone, southern Ethiopia, 2015

\begin{tabular}{|c|c|c|c|c|c|}
\hline \multirow[t]{2}{*}{ Variables } & & \multicolumn{3}{|l|}{ Water bodies } & \multirow[t]{2}{*}{ Total } \\
\hline & & Himbecho Irrigation & Kote Stream & Bisare Stream & \\
\hline Altitude (m.a.s.l) & & 1650 & 1802 & 1731 & \\
\hline \multirow[t]{3}{*}{ Snail species } & Bulinus species & 18 & 67 & 40 & 125 \\
\hline & Biomphalaria pfeifferi & 18 & 37 & 56 & 111 \\
\hline & Lymnaea natalensis & 4 & 13 & 3 & 20 \\
\hline Total collection (\%) & & $40(15.6)$ & $117(45.7)$ & 99 (38.7) & 256 \\
\hline Number of B. pfeifferi shedding schistosome cercariae & & 0 & 5 & 2 & 7 \\
\hline \multirow[t]{3}{*}{ Adult schistosome worms harvested after mice sacrificed } & Male & 0 & 527 & 83 & 610 \\
\hline & Female & 0 & 0 & 8 & 8 \\
\hline & Copula & 0 & 79 & 8 & 87 \\
\hline
\end{tabular}

lumbricoides were the major parasites identified in this study. The prevalence of hookworm infection (27.6\%) found in this study is higher than the estimated national prevalence $16 \%$ [31] and this is in line with previous studies done in the country [30-37]. On the other hand, the prevalence of $A$. lumbricoides (8.9\%) is quite lower than the estimated national prevalence 37\% [31]. There are previous studies which reported higher prevalence of ascariasis in the country [37-40]. Infections by E. vermicularis (2.8\%), Taenia species (2.6\%), T. trichiura (1.2\%) and $H$. nana $(0.6 \%)$ were also recorded at low prevalence in the present study. Such variations in prevalence of helminth infections are likely attributed to variations in appropriate water supplies, sanitation, hygiene (WASH), among other things.

The prevalence of S. mansoni infections in 503 school children of 5 selected primary schools in Wolaita Zone, southern Ethiopia was found out to be $58.6 \%$. This finding is lower than the previous $81.3 \% \mathrm{~S}$. mansoni infection prevalence reported from one of the primary schools, Demba Girara, in a village of the present study area [19]. The lower prevalence in the present study might be due to variation of localities from where the school children were sampled. The current finding on S. mansoni infection prevalence was also lower than the $82.8 \%$ prevalence reported from Sanja area, northern Ethiopia [35] and $73.7 \%$ from Bushulo village, southern Ethiopia [36]. On the other hand, the current $S$. mansoni infection prevalence is higher than similar studies done on school children [37-42]. The higher S. mansoni infection prevalence in the present study might be due to the absence of clean water supply, lack of awareness on the disease and hence the absence of schistosomiasis control measures in the study area. Inhabitants of the area largely depended on open water sources for domestic and recreational use. The fact that inhabitants of the study area have no awareness on the existence of schistosomiasis manifested in that the disease was highly neglected in the area. Open defecation near water sources might have also increased the transmission of $S$. mansoni in the present study area.

The higher S. mansoni prevalence among male children might be due to the observed higher frequency of contact with cercariae contaminated water bodies than females. This finding is in agreement with previous studies done elsewhere in the country [19, 43-46]. The increased $S$. mansoni infection among male children could also be due to herding cattle near cercariae contaminated water bodies as this is an outdoor activity which is mostly practiced by male children in the study area. Similar explanation was given by the study done previously around the present study area [19]. The variation in S. mansoni infection prevalence (ranged 5.1\% to $75 \%$ ) among the primary schools might be due to the differences in altitude, microclimate and level of dependency in open water sources of the localities. The lower prevalence $(5.1 \%)$ at Ello primary school might be due to relatively lower altitude (1400 m above sea level) of the area. In area with lower altitudes where the water environments experience relatively higher temperature which may affect survival of snail hosts and parasites [47].

All three classes of intensity of infection by $S$. mansoni were found in the present study with highest heavy infection intensities observed in the 10-14 years age group from age category, males from sex category, Motala from school category, those who had frequent water contact and those who swam in infectious water sources. The reason for finding higher heavy infection in these specified categories of children could be due to the frequent exposure to $S$. mansoni infection $[18,46,48]$. The agespecific association of infection intensity in current study is also in agreement with the finding of previous study done in a village close to the present study area [19]. The highest heavy infection intensity observed in Motala primary school might be attributed to the absolute dependency of inhabitants on Bisare stream which was 
highly infested with infected snails. The sanitary condition of water environment was also very poor as high fecal contamination was observed along the course of the stream in general and several human-water contact points in particular at Bisare.

The present study showed that the frequency of water contact was the most associated risk factor for $S$. mansoni infection in that school children who swam in rivers and streams were three times more likely to be infected with $S$. mansoni than those who did not swim. Other previous studies also found swimming to be a common risk factor for S. mansoni infection. Although herding cattle near streams and rivers was significantly associated risk factor to $S$. mansoni infection in the previous study done in a village of the study area [19], the present study found no statistically significant association with the activity.

S. mansoni endemicity speculated in earlier study [19] was confirmed by the present study through survey of snail intermediate host, shedding of $S$. mansoni cercaria from the B. pfeifferi snails and identification of the parasite in mice infection model. Survey for B. pfeifferi was conducted at water sources of areas where schistosomiasis is determined. The snail survey showed more abundant B. pfeifferi in Bisare and Kote streams than in Himbecho irrigation canal. Presence of less abundant $B$. pfeifferi in Himbecho irrigation canal might be due to sparse vegetation coverage of the canal. The slow water flow and abundant aquatic vegetation made Bisare and Kote streams favorable habitats for B. pfeifferi and other snails including Bulinus species and Lymnaea natalensis [16]. Even though Woibo and Adacha rivers were suspected for $S$. mansoni infection, only few young $B$. pfeifferi snails were observed along these rivers. The absence of adult $B$. pfeifferi snails could be due to the reason that the survey was made a week after unexpected heavy rainfall in the area due to the El Nino effect. Among the physical variables of water environment, substrate, vegetation density and water velocity are the strongest predictors of snail presence [49]. During the rains, snail occurrence and density are even more affected in relatively large streams and rivers [49]. In contrast to the high $S$. mansoni infection prevalence (58.6\%) found in this study, a very low proportion of B. pfeifferi snails collected in the present survey were shedding $S$. mansoni cercariae. This finding is in agreement with other studies done in endemic areas with high transmission where few or none of the snail hosts collected shed any schistosome cercariae [50, 51]. In a previous study done in Msambweni area, coastal province of Kenya, where high prevalence of human schistosomiasis occurred, it was observed that very low proportion of snails were found shedding schistosome cercariae [52]. Therefore, the higher schistosomiasis transmission in an area may not always coincide with the greater proportion of host snails shedding schistosome cercariae. The possible explanation given for this unexpected low cercariae shedding from the snail intermediate hosts, as mentioned in previous studies, could be the variation in percentage of infected snail, focal nature of schistosomiasis, dispersed distribution of infected snails and seasonal differences $[51,52]$.

\section{Conclusion}

The present study showed high level of intestinal helminth infections in the study area. The existence of schistosome infected B. pfeifferi and high prevalence of $S$. mansoni infection among school children confirm the endemicity of $S$. mansoni in the study areas. The high prevalence of intestinal helminth infections in general and the autochthonous transmission of S. mansoni infection in particular in the study area require implementation of preventive chemotherapy and also consideration of other complementary measures including sanitation, provision of clean water supply, and snail control.

\section{Abbreviations \\ EPG: Egg per gram of stool; STH: Soil-transmitted helminths; WHO: World Health Organization}

\section{Acknowledgements \\ The authors would like to thank Wolaita Sodo University (WSU) for hosting the study. We also acknowledge Aklilu Lemma Institute of Pathobiology (ALIPB), Addis Ababa University, for collaborative work on snail identification, cercariae shedding and mice infection and definite identification of the schistosome species. We are thankful to the laboratory and field technicians of WSU and ALIPB for their assistance during field and laboratory work. Mr. Sisay Dessie of ALIPB deserves a particular appreciation for his technical assistance in collecting and maintaining snails and mice in the laboratories. Our gratitude is also extended to the health and education offices of Wolaita Zone and their respective district administrators for their cooperation during the study period.}

\section{Funding}

Fund was obtained from Wolaita Sodo University to collection and process data for this research.

\section{Availability of data and materials}

The datasets used and/or analysed during the current study are available from the corresponding author on reasonable request.

\section{Authors' contributions}

BA conceived and designed the study, collected data in the field and performed data analysis. ZT and FW participated in data collection, assisted the design and reviewed the manuscript. DL participated in data collection, assisted laboratory and field works and reviewed the manuscript. SL participated in analysis and interpretation of data, critically revised the manuscript. BE participated in study design and interpretation of data and critically reviewed the manuscript. All authors read and approved the final version of the manuscript.

Competing interests

The authors have declared that no competing interests exist.

Consent for publication

Not applicable. 


\section{Ethics approval and consent to participate}

The protocol of this study was ethically reviewed and approved by the Ethical Review Committee of College of Natural and Computational Science in Wolaita Sodo University. Permissions were obtained from Wolaita Zone Health Department, District Health and Educational Bureaus to conduct the study. The objective of the study was explained to the school administration, primary health care providers and parents/guardian of the children. Verbal consent for the children was obtained from their parents/guardians. As most of the study population were illiterate, the ethical review committee endorsed oral consenting of the parents/guardians of the children. All children found positive for intestinal helminths were treated with appropriate drugs by nurses. The infection intensity and prevalence were reported to the Zonal and District Health Offices. The protocol for animal use was also reviewed and approved by the Ethical Review Committee of College of Natural and Computational Science in Wolaita Sodo University (Permit Number: EA-CNCS-07-R02). Handling of Swiss albino mice for sacrifice was performed under anesthesia, and all efforts were made to minimize suffering. The field study protocol of this research was also viewed and approved by the same ethical review committee.

\section{Publisher's Note}

Springer Nature remains neutral with regard to jurisdictional claims in published maps and institutional affiliations.

\section{Author details}

${ }^{1}$ Biomedical Sciences Division, Department of Biology, College of Natural and Computational Sciences, Wolaita Sodo University, Wolaita Sodo, Ethiopia. ${ }^{2}$ Microbiology Unit, College of Health Sciences and Medicine, Wolaita Sodo University, Wolaita Sodo, Ethiopia. ${ }^{3}$ Department of Environmental and Global Health, College of Public Health and Health Professions, University of Florida, Gainesville, FL 32610, USA. ${ }^{4}$ Aklilu Lemma Institute of Pathobiology, Addis Ababa University, Addis Ababa, Ethiopia.

\section{Received: 16 February 2017 Accepted: 12 June 2017}

\section{Published online: 20 June 2017}

\section{References}

1. WHO. Eliminating soil-transmitted helminthiasis. Geneva: WHO; 2012

2. WHO. Prevention and control of schistosomiasis and soil-transmitted helminthiasis: first report of the joint WHO expert committees. WHO Tech Rep Ser. 2002;912:1-57.

3. Chitsulo L, Engels D, Montresor A, Savioli L. The global status of schistosomiasis and its control. Acta Trop. 2000;77:41-51.

4. WHO. Preventive chemotherapy databank. Geneva: World Health Organization; 2012. Available from: http://www.who.int/neglected_diseases/ preventive_chemotherapy/databank/en/index.html. Accessed 28 Nov 2013.

5. Steinmann P, Keiser J, Bos R, Tanner M, Utzinger J. Schistosomiasis and water resources development: systematic review, meta-analysis, and estimates of people at risk. The Lancet Infect Dis. 2006:6:411-25.

6. Van der Werf MJ, De Vlas SJ, Brooker S, Looman CWN, Nagelkerke NJD, Habbema JD, et al. Quantification of clinical morbidity associated with schistosome infection in sub-Saharan Africa. Acta Trop. 2003;86:125-39.

7. Gryseels B, Polman K, Clerinx J, Kestens L. Human schistosomiasis. Lancet. 2006;368:1106-18.

8. Girma M, Mohamed A. Parasitology for medical laboratory technology students lecture note series. 2003.

9. Kloos H, Lo CT, Birrie H, Ayele T, Tedla S, Tsegay F. Schistosomiasis in Ethiopia. Soc Sci Med. 1988;26:803-27.

10. Gashaw F, Aemero M, Legesse M, Petros B, Teklehaimanot T, Medhin G, et al. Prevalence of intestinal helminth infection among school children in Maksegnit and Enfranz towns, northwestern Ethiopia, with emphasis on Schistosoma mansoni infection. Parasit Vectors. 2015;8:567.

11. Abebe N, Erko B, Medhin G, Berhe N. Clinico-epidemiological study of Schistosomiasis mansoni in Waja-Timuga,District of Alamata, northern Ethiopia. Parasit Vectors. 2014;7:158.

12. Degarege A, Mekonnen $Z$, Levecke B, Legesse M, Negash $Y$, Vercruysse J, et al. Prevalence of Schistosoma haematobium infection among school-age children in afar area. Northeastern Ethiopia PLoS ONE. 2015;10(8):e0133142.

13. Geleta S, Alemu A, Getie S, Mekonnen Z, Erko B. Prevalence of urinary schistosomiasis and associated risk factors among Abobo primary school children in Gambella regional state, southwestern Ethiopia: a cross sectional study. Parasit Vectors. 2015;8:215.
14. Erko B. Epidemiological Investigation and Intervention Trials towards the Control of Schistosomiasis in Ethiopia. Addis Ababa: Inaugural professorial lecture, Addis Ababa University; 2010.

15. Lo CT, Kloos H, Birrie H. Schistosomiasis. The ecology of health and disease in Ethiopia. Addis Ababa: Ministry of Health; 1988;196-213.

16. Lo CT, Redda A, Gemeda N. In: Ayele T, Lo CT, editors. Malacological studies of human schistosomiasis in Ethiopia. In proceedings of symposium on human Schistosomiasis in Ethiopia. Addis Ababa: Institute of Pathobiology, Addis Ababa University; 1982.

17. Erko B, Balcha F, Kifle D. The ecology of Biomphalaria Sudanica in Lake Ziway. Ethiopia Afr J Ecol. 2006:44:347-52

18. Birrie H, Abebe F, Gundersen SG, Medhin G, Berhe N, Gemetchu T. Epidemiology of Schistosomiasis mansoni in three endemic communities in north-east Ethiopia. Baseline characteristics before endod based intervention. Ethiop Med J. 1998;36:101-11.

19. Alemayehu B, Tomass Z. Schistosoma mansoni Infection prevalence and associated risk factors among school children in Demba Girara, Damot Woide District of Wolaita zone. Southern Ethiopia APJ Trop Med. 2015; 8(6):457-63.

20. CSA. Summary and statistical report of the 2007 population and housing census results. Federal Democratic Republic of Ethiopia: Population Census Commission. Addis Ababa: Central Statistical Agency; 2008.

21. SNNPR. Health profile of Wolaita Zone. Hawassa: Southern Nations Nationalities and Peoples Region Ethiopia; 2002.

22. Daniel WW. Biostatistics a foundation for analysis in the health science. 6th ed. New York: Willey; 1995. p. 155.

23. Peters PA, Alamy ME, Warren KS, Mahmoud AAF. Quick Kato smear for field quantification of Schistosoma mansoni eggs. Am J Trop Med Hyg. 1980; 29(2):217-9.

24. WHO. Basic laboratory methods in medical Parasitology. Geneva: World Health Organization; 1991.

25. WHO. Prevention of Schistosomiasis and soil transmitted helminthiasis. Report of WHO expert committee, WHO technical report series, vol. 912. Geneva: WHO; 2002.

26. Brown DS. Freshwater snails of Africa and their medical importance. 2nd ed. London: Taylor and Francis Limited; 2005.

27. Frandsen F, Christensen NO. An introductory guide to the identification of cercariae from African fresh water snails with special reference to cercariae of trematodes species of medical and veterinary importance. Acta Trop. 1984;41:118-202

28. Duval RH, Dewitt WB. An improved perfusion technique for recovering adult schistosomes from laboratory animals. Amer J Trop Med Hyg. 1967;16:483.

29. Hotez PJ, Brindley PJ, Bethony JM, King CH, Pearce EJ, Jacobson J. Helminth infections: the great neglected tropical diseases. J Clin Invest. 2008;118: 1311-21. doi:10.1172/JCl34261.

30. Alemayehu B, Tomass Z. Prevalence of intestinal Helminthiasis and associated risk factors among school children in Dawro zone, southern Ethiopia. J Biol Agr Heal Care. 2015;5:76-82.

31. Tadesse Z, Hailemariam A, Kolaczinski JH. Potential for integrated control of neglected tropical diseases in Ethiopia. Trans R Soc Trop Med Hyg. 2008; 2008(102):213-4

32. Yami A, Mamo Y, Kebede S. Prevalence and predictors of intestinal Helminthiasis among school children in Jimma zone; a cross- sectional study Ethiop. J Health Sci. 2011;21(3):167-74.

33. Erko B, Medhin G. Human helminthiasis in Wondo Genet, southern Ethiopia, with emphasis on geohelminthiasis. Ethiop Med J. 2003;41:333-4.

34. Alelign T, Degarege A, Erko B. Soil-Transmitted Helminth Infections and Associated Risk Factors among School children in Durbete Town, Northwestern Ethiopia. J Parasitology Research. 2015; Article ID 641602.

35. Alebie G, Erko B, Aemero M, Petros B. Epidemiological study on Schistosoma mansoni infection in Sanja area, Amhara region. Ethiopia Parasit Vectors. 2014;7:15.

36. Terefe A, Shimelis T, Mengistu M, Hailu A, Erko B. Schistosomiasis mansoni and soil-transmitted helminthiasis in Bushulo village, southern Ethiopia. Ethiop J Health Dev. 2011;25:46-50.

37. Assefa A, Dejenie T, Tomass Z. Infection prevalence of Schistosoma mansoni and associated risk factors among school children in suburbs of Mekelle city, Tigray, northern Ethiopia. Momona Eth J Sci. 2013;5:174-88.

38. Jejaw A, Zemene $E$, Alemu $Y$, Mengistie $Z$. High prevalence of Schistosoma mansoni and other intestinal parasites among elementary school children in Southwest Ethiopia: a cross-sectional study. BMC Public Health. 2015;15:600. 
39. Mathewos B, Alemu A, Woldeyohannes D, Alemu A, Addis Z, Tiruneh M, et al. Current status of soil transmitted helminths and Schistosoma mansoni infection among children in two primary schools in North Gondar, Northwest Ethiopia: a cross sectional study. BMC Res Notes. 2014;7:88.

40. Erko B, Medhin G. Human helminthiasis in Wondo Genet, southern Ethiopia, with emphasis on geohelminthiasis. Ethiop Med J. 2003:41(4):333-44.

41. Alemu A, Atnafu A, Addis Z, Shiferaw Y, Teklu T, Mathewos B, et al. Soil transmitted helminths and Schistosoma mansoni infections among school children in Zarima town, northwest Ethiopia. BMC Infect Dis. 2011;11:189.

42. Mitiku H, Legesse M, Teklemariam Z, Erko B. Transmission of Schistosoma mansoni in Tikur Wuha area, southern Ethiopia. Ethiop J Health Dev. 2010; 24:180-4.

43. Wolde Michael T, Endeshaw T, Shibre T, Gebre T, Haddis M, Tilahun D, et al Intestinal parasitic infection in western Abaya with special reference with Schistosomiasis mansoni. Ethiop J Health Dev. 1999:13:21-6.

44. Assefa T, Woldemmicale T, Dejene A. Intestinal parasitism among students in three localities in south Wello. Ethiopia Ethiop J Health Dev. 1998;12:231-5.

45. Roma B, Worku S. Magnitude of Schistosoma mansoni and intestinal helminthic infections among school children in Wondo Genet Zuria, southern Ethiopia. Ethiop J Health Dev. 1997;11:125-9.

46. Erko B, Tedla S, Petros B. Transmission of intestinal schistosomiasis in Bahir Dar, Northeast Ethiopia. Ethiop Med J. 1991:29:199-211.

47. McCreesh N, Booth M. The effect of increasing water temperatures on Schistosoma mansoni transmission and Biomphalaria Pfeifferi population dynamics: an agent-based Modelling study. PLoS One. 2014;9:e101462.

48. Alemu A, Tegegne Y, Damte D, Melku M. Schistosoma mansoni and soiltransmitted helminths among preschool-aged children in Chuahit, Dembia district, Northwest Ethiopia: prevalence, intensity of infection and associated risk factors. BMC Public Health. 2016;16:422. doi:10.1186/s12889-016-2864-9.

49. Kloos H, De Souza C, Gazzinelli A, Soares Filho BS, Temba PC, Bethony J, et al. The distribution of Biomphalaria spp. in different habitats in relation to physical, biological, water contact, and cognitive factors in a rural area in Minas Gerais, Brazil. Mem Inst Oswaldo Cruz. 2001:96:57-66.

50. Opisa S, Odiere MR, GZO Jura W, DMS K, PNM M. Malacological survey and geographical distribution of vector snails for schistosomiasis within informal settlements of Kisumu City, western Kenya. Parasit Vectors. 2011;4:226.

51. McClelland WF. Studies on snail vectors of schistosomiasis in Kenya. J Trop Med Hyg. 1956;59:229-42.

52. Kariuki HC, Clennon JA, Brady MS, Kitron U, Sturrock RF, Ouma JH, et al. Distribution patterns and cercarial shedding of Bulinus nasutus and other snails in the Msambweni area, Coast Province. Kenya Am J Trop Med Hyg. 2004;70:449-56.

\section{Submit your next manuscript to BioMed Central and we will help you at every step:}

- We accept pre-submission inquiries

- Our selector tool helps you to find the most relevant journal

- We provide round the clock customer support

- Convenient online submission

- Thorough peer review

- Inclusion in PubMed and all major indexing services

- Maximum visibility for your research

Submit your manuscript at www.biomedcentral.com/submit 